\title{
EVALUATION OF DENTAL MATURITY USING THE DEMIRJIAN'S METHOD IN ROMANIAN CHILDREN
}

\author{
EUGEN SILVIU BUD ${ }^{1}$, ANAMARIA BUD ${ }^{2}$, CRISTINA BICĂ ${ }^{3}$, OANA ELENA STOICA ${ }^{4}$, ADELIA- \\ ELENA OLTEAN ${ }^{5}$, ALEXANDRU VLASA $^{6}$, MARIANA PĂCURAR ${ }^{7}$, DANIELA EŞIAN ${ }^{8}$ \\ 1,2,3,4,6,7,8 University of Medicine, Pharmacy, Science and Technology, Tîrgu Mureș, ${ }^{5}$ Private Practice, Brașov
}

Keywords: dental age, Abstract: Demirjian's method is the most frequently used method of dental maturity estimation. The Demirjian's method, aim of this study was to assess the accuracy of the method in a sample of Romanian children. The chronological age, study was conducted on X-rays of 126 children with ages ranging from 5 to 15 years old. Dental age children was determined and t-tests were used to assess the difference between dental age and chronological age within each age category. The boys in our study have advanced dental age in all age groups, while the girls have only in the age categories 7 to 8 years, 9 to 10 years and 11 to 12 years. The results of our study show that the method is appropriate for Romanian children and that these standards are applicable only in certain age groups. Further research is required on a larger sample.

\section{INTRODUCTION}

Dental development and the eruption process are part of the general development of the child, being an indicator of maturity.(1) Several approaches have proven to be valuable in estimating dental age in children. The assessment of dental age, by observing the degree of mineralization of the teeth being formed on OPG radiographs, is a method with a high degree of safety, unlike the moment of eruption, gingival emergence. This method is not influenced by local factors, such as dental ankylosis, dental migrations with loss of space, orthodontic abnormalities, dental destruction with premature loss of temporary teeth etc. $(2,3)$ Thus, the degree of mineralization of the teeth, as a development process, is used in determining the dental age.(4) By calculating the difference between dental and chronological age and comparing it with standard values, we obtain information about an early or delayed eruption (5), without the need for additional radiographs with patient irradiation.

The clinical importance of knowing the dental age of a patient (which often does not correspond with chronological age) is of particular interest to orthodontists and pediatric dentists for planning the treatment of various types of malocclusion in relation to maxillofacial development.(6) It is essential to start treatment during the optimal period of growth in order to obtain the ideal correction of skeletal discrepancies. Orthodontic treatment can be initiated later in patients with delayed dental age leading to a shorter duration of treatment and more stable results over time. Knowing the dental age is useful for the use of functional appliances and the correct planning of orthognathic surgery and serial extractions.(7)

\section{AIM}

The aim of this study was to obtain the dental age based on OPG radiographs using the Demirjan's method and to evaluate the applicability of the method on a Romanian children population and to compare our results with studies on other populations from various other countries.

\section{MATERIALS AND METHODS}

In this cross-sectional study, the orthopantomographs of 126 healthy children ( 59 boys and 67 girls) with no history of congenital and systemic disorders from the cities of TârguMures and Brașov, central Romania, were reviewed and the dental age was determined using the Demirjian's method. The ages ranged from 5 to 15 years old. All graphs were analysed and scored by one examiner using the Demirjian's method to obtain dental age.

Subjects were divided into 2 groups, first based on gender. They were further divided into 5 groups, each corresponding to a 2-year age range.

The inclusion criteria were:

- $\quad$ only children from central Romania

- 5 to 15 year-old

- $\quad$ healthy children with no history of congenital and systemic disorders

- $\quad$ good quality radiographs

- $\quad$ no missing left permanent mandibular teeth

The chronological age (CA) is the actual age of the patient and was calculated for each subject using the date on which the X-ray was taken and the date of birth of the patient. It was then converted into a decimal number.

The estimation of the dental age (DA) was performed following the Demirjan's method which uses the degree of development of the seven mandibular teeth (except for the third molar). Every tooth was assigned a rating from " $\mathrm{A}$ " to " $\mathrm{H}$ ". The stages were next transformed to scores with the use of specific to gender conversion tables. A total maturity score, was then calculated for each tooth. The score was converted into dental age using standard tables developed by the authors. The dental development stages according to Demirjian are (8):

Stage A: The onset of calcification is detected at the superior level of the crypt with the feature of an inverted cone or cones. No fusion of these calcification points is noticed.(8)

Stage B: The unification of the calcified points results into one or several cusps which form a unite a defined occlusal

'Corresponding author: Anamaria Bud, Str. Nicolae Grigorescu Nr. 3, Târgu-Mureș, Mureș, E-mail:anamaria_jurca@yahoo.com, Phone: +40720 540925

Article received on 26.03.2021 and accepted for publication on 31.05.2021

AMT, vol. 26, no. 2, 2021, p. 48 


\section{CLINICAL ASPECTS}

surface.(8)

Stage C: Enamel development is finished at the occlusal surface; the process of dentine deposition has begun and the pulp chamber is shaped in as a curve at the occlusal border.(8)

Stage D: The crown is completely formed, until the cemento-enamel junction. The root formation is visible in the form of a spicule. (8)

Stage E: The pulp chamber walls form straight lines The crown height is larger than the root length. In molars, the development of the radicular bifurcation has the aspect of a semi-lunar shape.(8)

Stage F: The walls of the pulp chamber form an isosceles triangle. The apex has the shape of a funnel. The crown height is equal or smaller than the root length.(8)

Stage G: The apical end of the root canal is still partially open. The root canal walls are parallel.(8)

Stage $\mathrm{H}$ : The roots apex is completely closed and the periodontal membrane has a uniform width.(8)

All panoramic radiographs were in digital format so that they could be analysed under magnification.

Figure no. 1. Demirjian's scoring on an OPG in the case of an 8.1-year-old girl

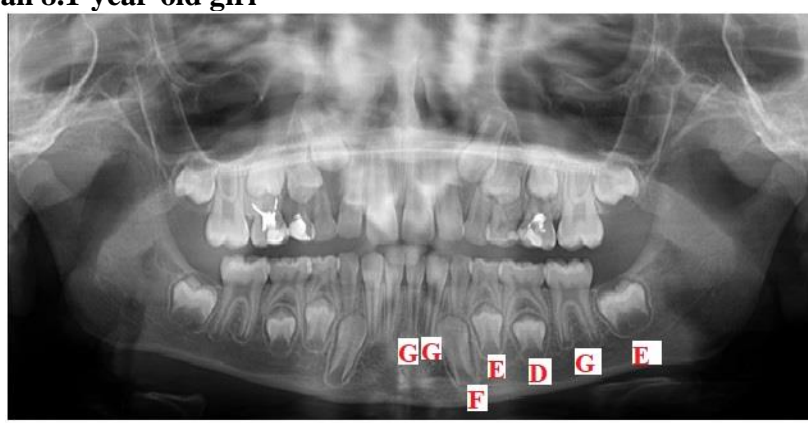

\section{RESULTS}

To compare the chronological age with the dental age of the children, the $\mathrm{T}$ Excel Test from the Microsoft Excel program was used.

Figure no. 2. Sample distribution by gender

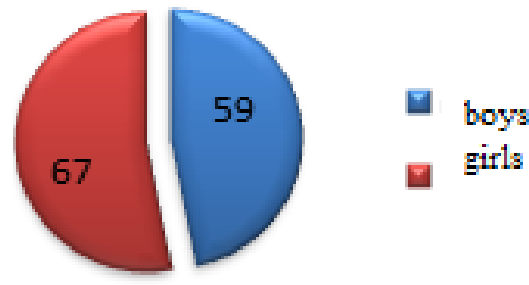

Figure no. 3. Sample distribution by age

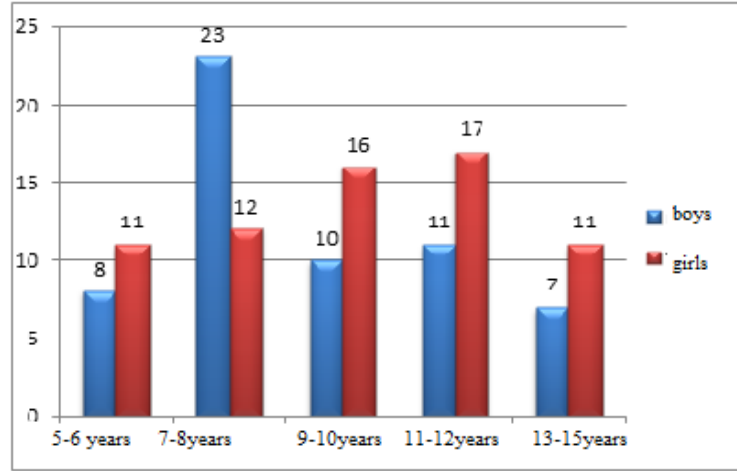

Tables no. 1 and 2 show the comparison between dental age (obtained using the Demirjan index) and chronological age in girls and boys, by age groups.

Table no. 1. Comparison between chronological and dental age in girls

\begin{tabular}{|c|c|c|c|c|c|c|c|}
\hline $\begin{array}{c}\text { Age } \\
\text { Groups }\end{array}$ & 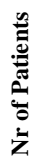 & 䒿 & 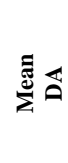 & 胥 & 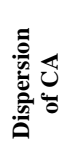 & 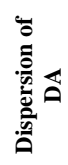 & $\mathbf{P}$ \\
\hline $5-6$ years & 11 & 6.32 & 6.21 & -0.11 & 0.118 & 0.176 & 0.20141 \\
\hline $7-8$ years & 12 & 8.15 & 8.33 & 0.17 & 0.145 & 1.047 & 0.52340 \\
\hline $\begin{array}{l}9-10 \\
\text { years }\end{array}$ & 16 & 10.10 & 10.52 & 0.41 & 0.381 & 1.418 & 0.07811 \\
\hline $\begin{array}{l}11-12 \\
\text { years }\end{array}$ & 17 & 11.79 & 12.62 & 0.82 & 0.219 & 1.625 & 0.00631 \\
\hline $\begin{array}{l}13-14 \\
\text { years }\end{array}$ & 11 & 13.98 & 13.88 & -0.10 & 0.343 & 0.287 & 0.36195 \\
\hline
\end{tabular}

Table no. 2. Comparison between chronological and dental age in boys

\begin{tabular}{|c|c|c|c|c|c|c|c|}
\hline $\begin{array}{c}\text { Age } \\
\text { Groups }\end{array}$ & 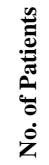 & 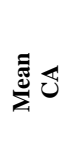 & 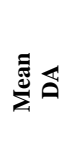 & $\stackrel{\text { Eี }}{\mathrm{E}}$ & 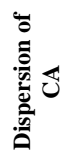 & 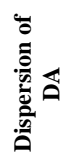 & $\mathbf{P}$ \\
\hline $5-6$ years & 8 & 5.61 & 6.08 & 0.46 & 0.324 & 0.413 & 0.05496 \\
\hline $7-8$ years & 23 & 7.81 & 8.36 & 0.54 & 0.284 & 0.202 & 0.00003 \\
\hline $9-10$ years & 10 & 10.17 & 10.57 & 0.40 & 0.535 & 1.945 & 0.15845 \\
\hline $\begin{array}{l}11-12 \\
\text { years }\end{array}$ & 11 & 11.69 & 12.70 & 1.00 & 0.250 & 0.670 & 0.00001 \\
\hline $\begin{array}{l}13-14 \\
\text { years }\end{array}$ & 7 & 14.18 & 14.20 & 0.02 & 0.188 & 0.677 & 0.91586 \\
\hline
\end{tabular}
groups (7-8 years, 9-10 years, 11-12 years) in the case of girls. The remaining 2 age groups (5-6 years and 13-14 years) having an underestimated dental age (figure no. 4). In the case of boys, an overestimation of dental age is observed in all age groups (figure no. 5).

Figure no. 4. Graphic representation of the over- and underestimation of dental age in girls

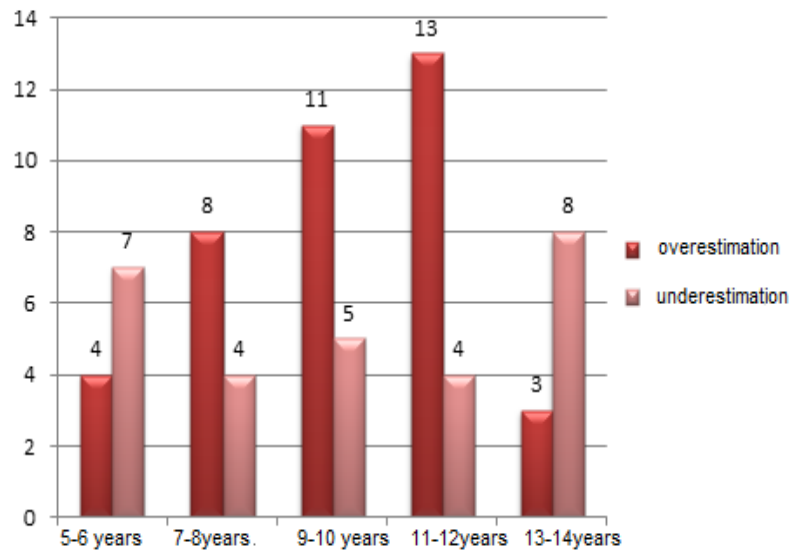

Table no. 3. Comparison between the chronological age and the dental age of the group of patients

\begin{tabular}{|l|l|l|l|l|l|}
\hline & $\begin{array}{c}\text { Nr. of } \\
\text { patients }\end{array}$ & $\begin{array}{c}\text { Mean } \\
\text { CA }\end{array}$ & $\begin{array}{c}\text { Mean } \\
\text { DA }\end{array}$ & DA-CA & P \\
\hline Girls & 67 & 10.20 & 10.50 & 0.31 & 0.00566577 \\
\hline Boys & 59 & 9.39 & 9.92 & 0.53 & 0.00000006 \\
\hline
\end{tabular}




\section{CLINICAL ASPECTS}

Figure no. 5. Graphic representation of the over- and underestimation of dental age in boys

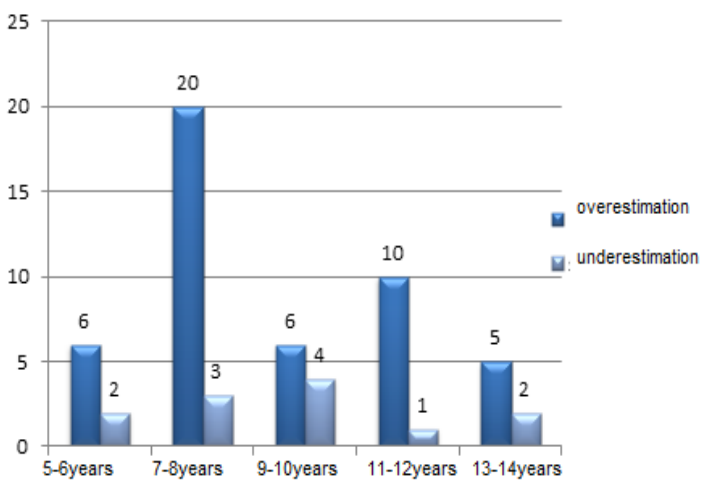

The mean difference between dental age and chronological age on the total number of patients was 0.53 years in boys and 0.31 years in girls (table no. 3 ), and statistical tests showed that the difference between them is statistically significant $(\mathrm{p}<0.001$, alpha $=0.05)$. The differences between chronological age and dental age ranged from 0.02 to 1.00 years in boys and -0.11 to 0.82 years in girls. The smallest age difference was found in the age group 13-15 years in both genders, namely 0.02 years in boys and -0.10 years in girls. We found statistically significant differences $(p<0.001)$ in girls in the age group 11-12 years, a difference of 0.82 years. In the case of boys there was a difference of 0.54 years in the age group 7-8 years and a difference of 1.00 years and in the group 11-12 years. No increase or decrease in age-related differences can be observed.

\section{DISCUSSIONS}

Estimating the growth and development of children from a medical and dental point of view is of great value. $(8,9)$ Tooth formation is widely used to assess growth and maturity. There are several methods that allow both age prediction and maturity estimation.(10) Demirjan's method is one of the simplest, most practical and widely used.(11) Its graphs are an attempt to provide international ways to assess dental maturity in children.(10)

Dental development varies between populations around the world, but even between areas of the same country.(12) This study was done to compare the estimated dental age of a group of children in central Romania with that of Canadian children of French origin from Demirjan's study.

Compared to the standard tables of the Demirjan method, the boys in our study have advanced dental age in all age groups, while girls only in the age categories 7-8 years, 9-10 years and $11-12$ years. The average difference was 0.31 years in girls and 0.53 years in boys. The results of the current study are similar with other studies conducted by Ogodescu et al. on children in Romania, where girls have significantly higher dental age in the age groups 5.5-6.4 years and 11.5-14.4 years.(13) The studies conducted by Ogodescu (13) revealed that boys had a higher dental age in all groups, except for the limit ones (6.6-7.4 years and 13.5-14.4 years) (13), while our study found higher values at all ages.

We also compared the results of our study with studies conducted in other countries on a Caucasian population, but also with Indian and Black populations. There are several studies in which dental age is lower than the chronological age. Compared to the standard values of the Demirjan's method, a study of Turkish children in the Anatolian Region showed a delayed dental age of -0.38 years in the entire study group with 0.33 in girls and 0.48 in boys.(14) In a group of Dutch children, Leurs showed that dental age was lower than chronological by -0.6 years in girls and -0.4 in boys.(6) Similar data with lower dental age were reported in Sudan on a study by Rizig who found an underestimation of the age of 1.42 years in girls and 0.70 years in boys.(15) On the population of North China studies showed that the Demirjan's method underestimated dental age by -0.47 years in boys and -0.63 years in girls.(16) Overestimation of dental age has been reported frequently in specialized studies.(17)

Results of studies with advanced dental age were obtained in groups in the Nordic countries. In case of Sweden the differences were between 0.4 and 1.8 years in boys and between 0.5 and 1.8 years in girls.(18) In the case of Norway, the differences were 0.2 years for boys and 0.3 years for girls (19) while in case of Finland the differences were 0.7 boys and 0.9 years for girls.(20) In Eastern Europe, a number of the studies were done, including in Poland and Serbia. Poland both boys and girls showed advanced dental age (21), same case with Serbia where there was an advance of 0.45 years for boys and 0.42 years for girls. (22)

Outside Europe, the data also show an increase in dental age as follows: Iranian children presented an advance of 0.15 years in girls and 0.21 years in boys (23), the population in western China an advance of 1.25 years for girls and 1.3 years for boys (24), the western part of the population of Saudi Arabia and increase between 0.64 and 1.44 for girls and between 0.66 and 0.77 for boys.(25)

According to the authors this overestimation can be partially explained by the advanced development observed in the last 35 years. Other differences between populations can be explained by environmental factors such as socio-economic status, nutritional status, eating habits and lifestyle.(26) We need to consider that any difference between the standard population and the study groups may be due to several variables, including method accuracy, examiners subjectivity, group age, group size, statistical approach, and individual biological or socioeconomic variations.(14)

\section{CONCLUSIONS}

Dental maturity indices are the most useful and reliable indicators of development, showing the least variability and not being influenced by exogenous factors.

The Demirjian's method is a frequently used, noninvasive, simple and practical method that clearly defines the stages of tooth development, allowing a correct estimate of dental age, using OPG radiographs, without the need for further investigation. Estimating the dental age by the Demirjian's method allows the appreciation of the degree of maturity, allowing the choice of the optimal moment to initiate the orthodontic and pedodontic treatment. These findings show the neeed for new specific standards and an additional research on a larger sample size.

\section{REFERENCES}

1. Varghese ST, Kumar V, Paul S, Jose LK, Mathew T, Siddique S. Estimation of Dental and Bone Age in Obese Children of South India. J Int Soc Prev Community Dent. 2018;8(2):153-159.

2. Jurca A, Lazar L, Pacurar M, Bica C, Chibelean M, Bud E. Dental Age Assessment Using Demirjian'S Method - a Radiographic Study. ESJ.2014;10 (36):1857-1881

3. Nicholas CL, Thalji G, Richter A. Childhood obesity and accelerated timing of dental development: A critical review. Forensic Anthropology. 2018;1(3):170-179.

4. Kumar V, Venkataraghavan K, Krishnan R, Patil K, Munoli K, Karthik S. The relationship between dental age, bone age and chronological age in underweight children. J 


\section{CLINICAL ASPECTS}

Pharm Bioall Sci . 2013;5(Suppl 1):S73-S79.

5. Esenlik E, Atak A, Altun C. Evaluation of dental maturation in children according to sagittal jaw relationship. Eur J Dent. 2014;8:38-43.

6. Leurs IH, Wattel E, Aartman IHA, Etty E et al.- Dental age in Dutch children. Eur. J. Orthod. 2005; 27:309-314.

7. Bhanat S, Pate D. Dental \& skeletal maturity indicators of Chronological age: Radiographic evaluation amongst children in Gujarat, India ,IOSR-JDMS. 2013;6:6-12.

8. Demirjian A, Goldstein H, Tanner JM.. A new system of dental age assessment. Hum Biol. 1973;45:211-27.

9. Chen JW, Guo J, Zhou J, Liu RK,Chen TT, Zou SJAssessment of dental maturity of western Chinese children using Demirjian's method,Forensic Sci Int. 2010;197:1-3.

10. Mentes A, Ergeneli S, Tanboga I.Applicability of Demirjian's standards to the Turkish children's dental age estimation. J Marmara Univ Dent Fac. 2000;4:63-68.

11. Garamendi PM, Landa MI, Ballesteros J, Solano MA. Reliability of the methods applied to assess age minority in living subjects around 18 years old. A survey on a Moroccan origin population. Forensic Sci Int .2005;154:312.

12. Celik S, Zeren C, Celikel A, Yengil E, Altan A. Applicability of the Demirjian method for dental assessment of southern Turkish children. J Forensic Leg Med. 2014;25:1-5.

13. Ogodescu E, Bratu, E, Tudor A et al. Estimation of child's biological age based on tooth development, Rom J Leg Med. 2011;(19) 115-124.

14. Karataş OH, Öztürk F, Dedeoğlu $N$ et al. Dental age assessment: The applicability of Demirjian method in southwestern of eastern Anatolia region Turkish children. Cumhuriyet Dent J. 2012;15(2):130-137.

15. Rizig AO, Elamin F, Zeidan ZA, Kasim $\mathrm{K}$ et al.Age Estimation and Dental Maturity for Sudanese Children Using Demirjian's System. J Med Med Sci. 2013;4(3):123127.

16. Zhai Y, Park H, Han J, Wang H, Ji F, Tao J. Dental age assessment in a northern Chinese population. J Forensic Leg Med. 2016;38:43-9.

17. Jayaraman J, Roberts GJ, King NM, Wong HM.-Dental age assessment of southern Chinese using the United Kingdom Caucasian reference dataset, Forensic Sci Int. 2012;216:6872 .

18. Mornstad H, Reventlid M, Teivens. AThe validity of four methods for age determination by teeth in Swedish children: a multicentre study. Swed Dent J. 1995;19(4):121-30.

19. Nikanen R, Espeland L, Kvaal SI, Krogstad O-Validity of the Demirjian method for dental age estimation when applied to Norwegian children. Acta Odontol Scand. 1998;56(4):238-44.

20. Nystrom M, Haataja J, Kataja M, Evalahti M, Peck L, Kieemola-Kujala E.-Dental maturity in Finnish children, estimated from the development of seven permanent mandibular teeth. Acta Odontol Scand. 1986;44(4):193198.

21. Rózylo-Kalinowska I, Kiworkowa-Raczkowska E, Kalinowski P.Dental age in Central Poland. Forensic Sci Int. 2008;174:207-16.

22. Djukic K, Zelic K, Milenkovic P, Nedeljkovic N, Djuric M. Dental age assessment validity of radiographic methods on Serbian children population. Forensic Sci Int. 2013;231(13):398.

23. Bagherian A, Sadeghi M. Assessment of dental maturity of children aged 3.5 to 13.5 years using the Demirjian method in an Iranian population. J Oral Sci. 2011;53(1):37-42.
24. Chen JW, Guo J, Zhou J, Liu RK, Chen TT, Zou SJ. Assessment of dental maturity of western Chinese children using Demirjian's method. Forensic Sci Int. 2010;197(13):119.e1-4.

25. Amin M, Kruger E, Tennant M. Dental age assessment of 4-16 year old Western Saudi children and adolescents using Demirjian's method for forensic dentistry. Egypt. J Forensic Sci. 2016;6:152-156.

26. Koshy S, Tandon S. Dental age assessment: the applicability of Demirjian's method in south Indian children. Forensic Sci Int. 1998;94:73-85. 